\title{
A non-linear masonry infill macro-model to represent the global behaviour of buildings under cyclic loading
}

\author{
H. Rodrigues $\cdot$ H. Varum $\cdot$ A. Costa
}

Received: 22 November 2006/Accepted: 3 March 2008/Published online: 1 April 2008

(C) Springer Science+Business Media, B.V. 2008

\begin{abstract}
The presence of masonry infill walls in $\mathrm{RC}$ buildings is very common. However, and even today, in the design of new buildings and in the assessment of existing ones, these infill walls are usually considered as non-structural elements and their influence in the structural response is generally ignored. For horizontal loading, infill panels can drastically modify the response, attracting forces to parts of the structure that have not been designed to resist them. This paper presents an improved nonlinear numerical simulation model for the influence of the masonry infill walls in the seismic behavior of structure. The model is implemented in the PORANL program. After the implementation and calibration of the proposed masonry model, a series of non-linear dynamic analyses of a building representative of Modern Architecture in Europe were carried out. The main objective was to investigate the behavior of this type of building, and any weakness under seismic loading. The building geometry and the dimensions of the RC elements and infill walls were set in the original project, and confirmed in the technical visits. The building under study has nine storeys and the structure is mainly composed of 12 plane frames oriented in the transversal direction. The building was
\end{abstract}

H. Rodrigues $\cdot$ H. Varum $(\bowtie) \cdot A$. Costa

Civil Engineering Department, University of Aveiro,

Campus Universitário de Santiago,

3810-193 Aveiro, Portugal

e-mail: hvarum@civil.ua.pt analyzed with a simplified plane model, for each direction, and the existing infill panels were looked at in accordance with their dimensions and location. The earthquake action adopted in this study was simulated through three series of artificially generated earthquakes, for a medium/high seismic risk scenario in Europe.

Keywords Infill masonry · Non-linear modeling · RC buildings - Seismic behavior .

Structural vulnerability

\section{Influence of infill masonry walls on the structural seismic response}

It is incorrect to assume that masonry infill panels are always beneficial to the structural response of buildings. The contributions of the infills to the building's seismic response can be positive or negative, depending on a series of phenomena and parameters such as, for example, relative stiffness and strength between the frames and the masonry.

In recent earthquakes, numerous buildings have been severely damaged or have collapsed because of the structural modifications to the basic structural system induced by the non-structural masonry partitions (Fig. 1). Even if they are relatively weak, masonry infill walls can drastically modify the structural response. 

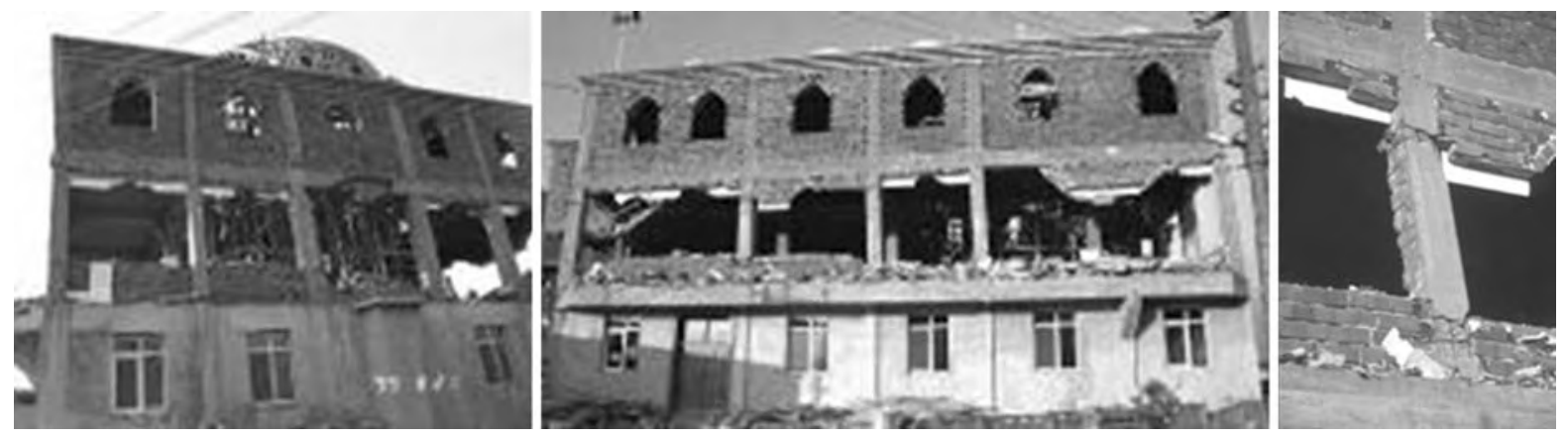

Fig. 1 Damage to masonry infill walls

Masonry infill panels can substantially increase the global stiffness of the structure. Consequently, its natural period will decrease. Vulnerable behavior may also result as a function of the extent to which masonry walls are built, such is the case when the walls only extend to part of the storey-height (shortcolumns), leaving a relatively short portion of the columns exposed. Frequently, a column is shortened by elements which have not been taken into account in the global structural design such as, for example, window openings or staircase landing slabs (Varum 2003).

\section{Proposed masonry infill panel model}

The infill masonry models can be classified as either micro or macro models. In the micro-models, infill panels are modeled with detailing at the components level: mortar, bricks, and interface mortar/brick elements. With the micro-models, a more accurate representation of the infill panels' behavior can be obtained. However, a large number of parameters have to be calibrated and an enormous calculation made. They can be useful for local analysis, but impractical for the global analysis of a building (Rodrigues 2005a).

Macro-models are more simplified and allow for the representation of the infill panels' global behavior and its influence in the building's structural response. The macro-model most commonly used is the bidiagonal equivalent-strut model. Many other examples of macro-models can be found in the literature: (i) homogenized frames sections; (ii) theory of plasticity; (iii) behavior coefficients, among others.

The macro-model proposed in this paper is an improvement on the commonly used equivalent bi-diagonal-strut model. It takes into account the interaction of the masonry panel's behavior in the two directions. In order to represent a masonry panel we considered four support strut-elements with rigidlinear behavior; and a central element in which the nonlinear hysteretic behavior is concentrated (Fig. 2a).

The non-linear behavior is characterized by a multi-linear envelop curve, defined by nine

(a)

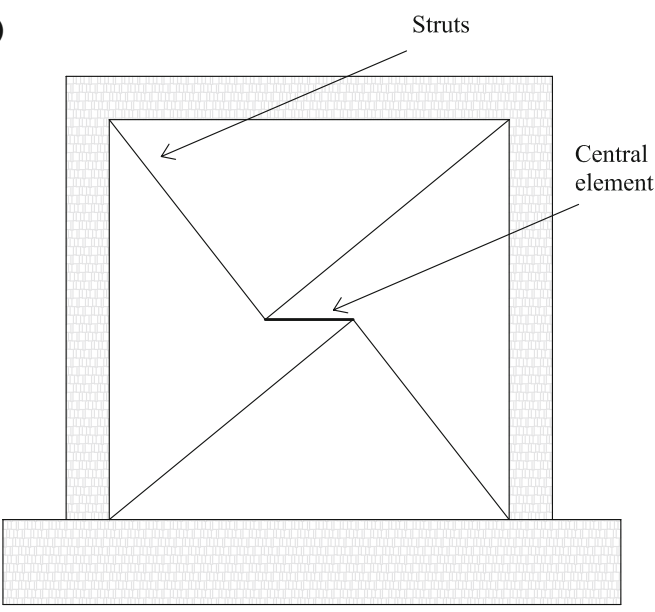

(b)

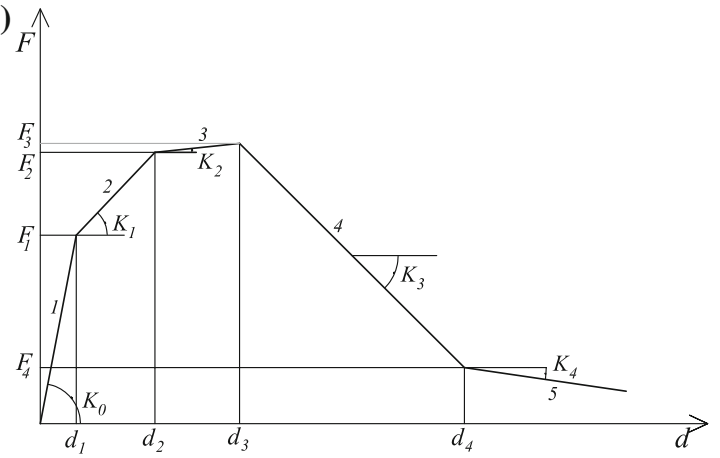

Fig. 2 Implemented strut model and force-displacement monotonic behavior curve 
Fig. 3 Hysteretic rules for the implemented model

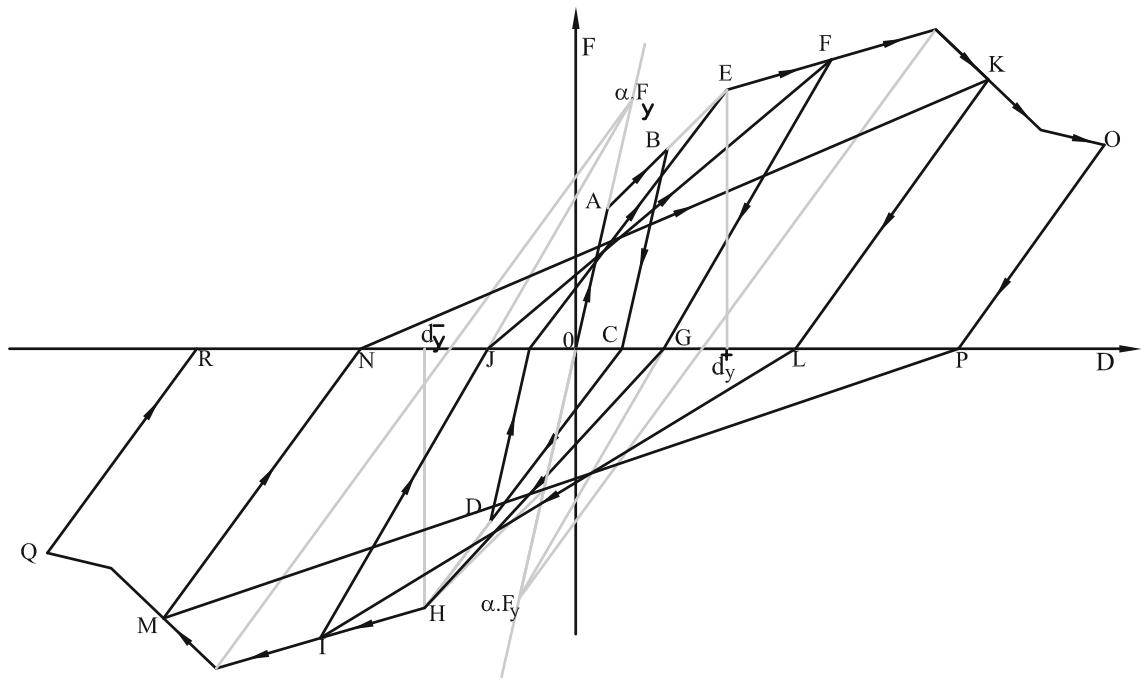

parameters (Fig. 2b), representing: cracking, peak strength, stiffness decreasing after peak strength and residual strength, for each direction, which allows for the consideration of the non-symmetrical behavior. The hysteretic rules calibrated for masonry models are controlled by three additional parameters, namely: $\alpha$-stiffness degradation; $\beta$ - "pinching" effect; and, $\gamma$-strength degradation.

The non-linear behavior of the central element is characterized by hysteretic rules based on the Takeda model (Costa 1989), as illustrated in Fig. 3. This thus permits the determination of response to the loading history as a function of the material's behavior (defined by the envelop curve and hysteretic parameters), and represents mechanical effects such stiffness and strength degradation, pinching effect, and internal cycles (Rodrigues et al. 2005b).

The monotonic behavior curve of each panel depends on the panel's dimensions, the dimensions and positions of any openings, material properties (bricks, mortar, and plaster), quality of the building work, and interface conditions between the panel and surrounding RC elements. This behavior may be determined from empirical expressions or experimental results (Zarnic and Gostic 1998).

\section{Hysteretic rules of the infill masonry model}

The non-linear behavior of the central element is characterized by hysteretic rules which allows the determination of its response to cyclic loads, in accordance with the material's behavior (defined by the envelop curve and hysteretic parameters). The hysteretic rules are briefly exemplified in Fig. 3.

Loading rules: The loading stiffness depends on the maximum force and displacement value reached in the previous cycle $\left(F_{\max }\right.$ and $\left.d_{\max }\right)$. The loading begins at the point corresponding to null-force $\left(d_{r}\right)$ and its stiffness is defined by the Eq. 1:

$K_{r}=\frac{F_{\max }}{d_{\max }-d_{r}}$

Unloading rules: Unloading takes place when a load inversion occurs. The unloading stiffness depends on the previously reached maximum displacement. Before the yielding-point has been reached, the unloading stiffness $\left(K_{d}\right)$ will be equal to the initial stiffness $\left(K_{0}\right)$. If the maximum displacement reached is larger than the yielding displacement, but smaller than the cracking displacement $\left(d_{\mathrm{cr}}\right)$, the unloading stiffness $\left(K_{d}\right)$ will depend on the parameter $\alpha$, and on the maximum displacement reached in that cycle, defined by:

$K_{d}=\frac{F_{\mathrm{cr}}-\alpha \cdot F_{y}}{K_{0} \cdot d_{\mathrm{cr}}+\alpha \cdot F_{y}} \cdot K_{0}$

If the maximum displacement reached is larger than $d_{\text {cr }}$, the unloading stiffness $\left(K_{d}\right)$ will depend only on the parameter $\alpha$. The unloading stiffness is given by Eq. 3:

$K_{d}=\frac{F_{\mathrm{cr}}-\alpha \cdot F_{y}}{d_{\mathrm{cr}} \cdot K_{0}-\frac{\alpha \cdot F_{y}}{K_{0}}} \cdot K_{0}$ 
"Pinching" effect: Simulates the closing of the masonry cracks in the unloading-reloading branch. The pinching effect is numerically represented by dividing the reloading branch into two branches with different stiffness. The pinching effect is controlled through the parameter $\beta$, and depends on the previously reached maximum displacement (see Eq. 4), where: $d_{r}$ is the displacement corresponding to null force in the previous cycle; $d_{y}$ is the yielding displacement.

$K=\frac{F_{\max }}{d_{\max }-d_{\mathrm{dr}}} \cdot\left(\frac{d_{y}}{d_{\max }}\right)^{\beta}$

Stiffness degradation: The stiffness degradation is controlled by the parameter $\alpha$ (Eq. 2).

Strength degradation: The strength degradation, for repeated cycles of a given displacement amplitude, was implemented by taking into account the interaction between the degradation of one direction with the other. The strength degradation is given by Eqs. 5-7, where: $\mathrm{PD}_{1}$ and $\mathrm{PD}_{2}$ are the degradation factors in direction 1 and $2 ; d_{i}$ is the displacement in the cycle $i ; d_{y}$ is the yielding displacement; $\mu, c, n$ and $\xi$ are constant parameters that are calibrated with experimental results or empirical formulas.

$\gamma=c \cdot \sum_{i=1}^{N} \frac{d_{i}}{d_{f}}$

$d_{f}=d_{y} \cdot \mu$

$\mathrm{PD}_{1}=\frac{e^{n \gamma}-1}{e^{n}-1} \cdot\left(1-\frac{\mathrm{PD}_{2}}{\zeta}\right)$

Internal cycles: When a load inversion happens, before the maximum force or displacement is reached, the model is able to reproduce the so-called internal cycles, with all the effects described above.

\section{RC elements}

In recent research involving the analysis of structures subjected to seismic actions, the use of non-linear behavior laws and hysteretic rules has proved to be a great advantage, because it enables a more rigorous representation of the seismic structural response.

The computer program PORANL was used to simulate the structural behavior of the building described in the previous section. This accounts for the non-linear bending behavior of RC elements (beams and columns) and the influence of the infill masonry panels.

Each RC structural element is modeled by a macro-element defined by the association of three bar finite elements, two with non-linear behavior at its extremities (plastic hinges), and a central element with linear behavior, as represented in Fig. 4.

The non-linear monotonic behavior curve of a cross-section is characterized through a tri-linear moment-curvature relationship, corresponding to the initial non-cracked concrete, concrete cracking and steel reinforcement yielding (Varum 1996). The monotonic curve is obtained using a fiber model procedure (see Fig. 5), from the geometric

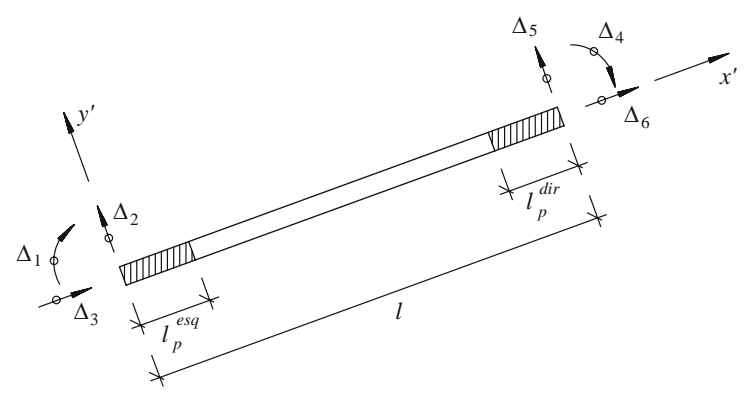

Fig. 4 Frame macro-element
Fig. 5 General fiber model for RC elements
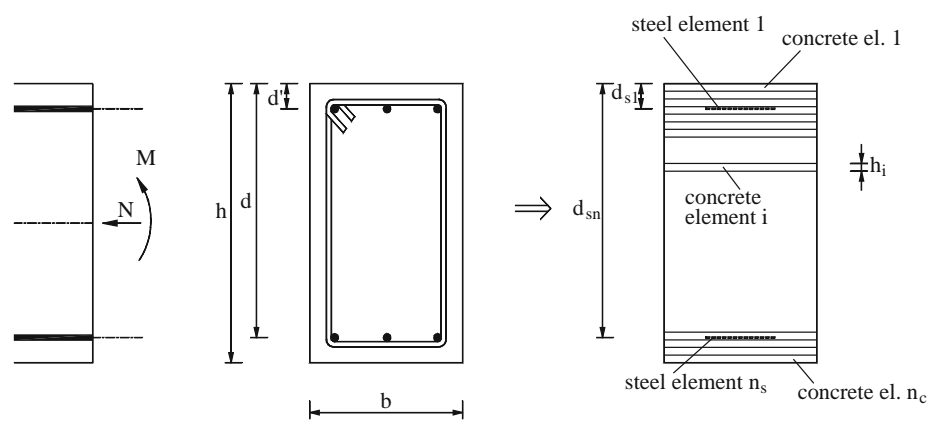
Fig. 6 Hysteretic model for RC elements

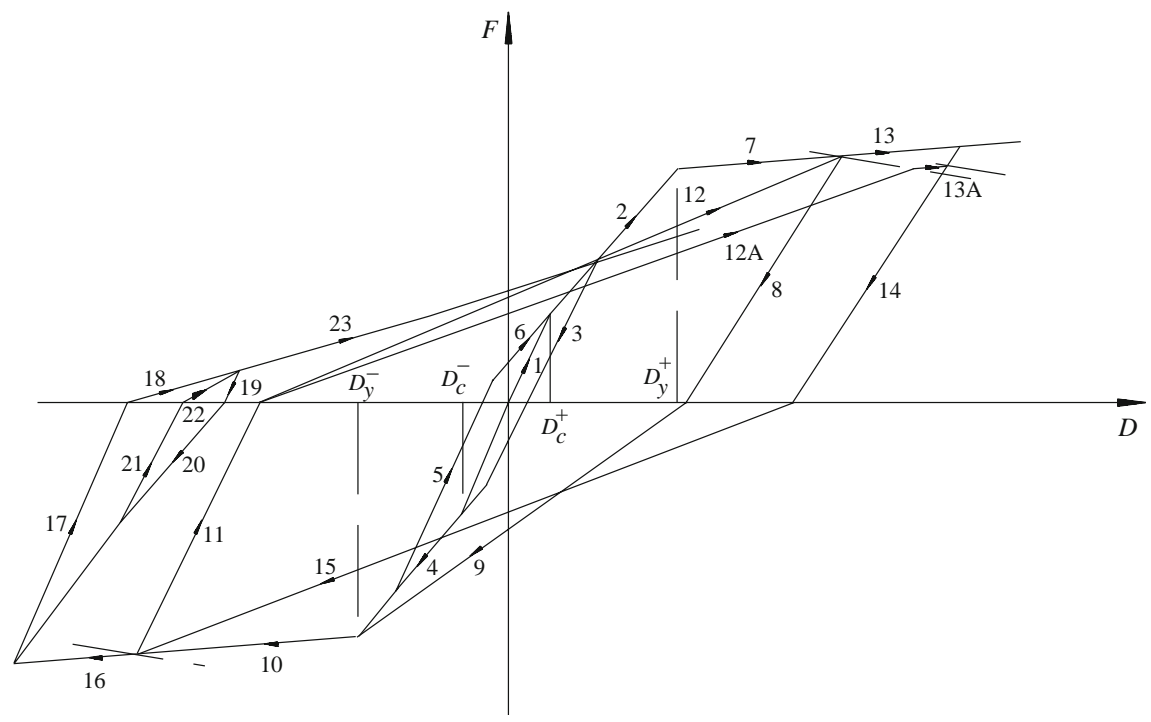

characteristics of the cross-sections, reinforcement and its location, and material properties.

The non-linear behavior of the plastic hinge elements is controlled through a modified hysteretic procedure, based on the Takeda model, as illustrated in Fig. 6. This model, developed by Costa (1989), represents the response evolution of the global RC element to seismic actions and accounts for such mechanical behavior effects as stiffness and strength degradation, pinching effect, slipping, internal cycles, etc.

\section{Case study}

The development and calibration of refined numerical tools, together with assessment and design codes, make the structural safety assessment of existing buildings feasible. In order to investigate the vulnerability of these types of buildings, which are very common in Lisbon, a building on the Avenue Infante Santo, which is representative of Modern Architecture, was subject to analysis. The building was studied using the non-linear dynamic analysis program PORANL, which allows the carrying out of a safety evaluation in accordance with the recently proposed standards (ATC-40 1996; and VISION2000 1995).

The 3rd Unity Type A lot in the Infante Santo Avenue in Lisbon is a singular example of a Modern Housing Project in Portugal (see Fig. 7). This building was part of an Urban Plan launched by Alberto José Pessoa (1919-1985), in 1947, when he joined the "Urbanization Study on the Protection Area of the Palácio das Necessidades" at the Câmara Municipal of Lisbon (CML). This project involved
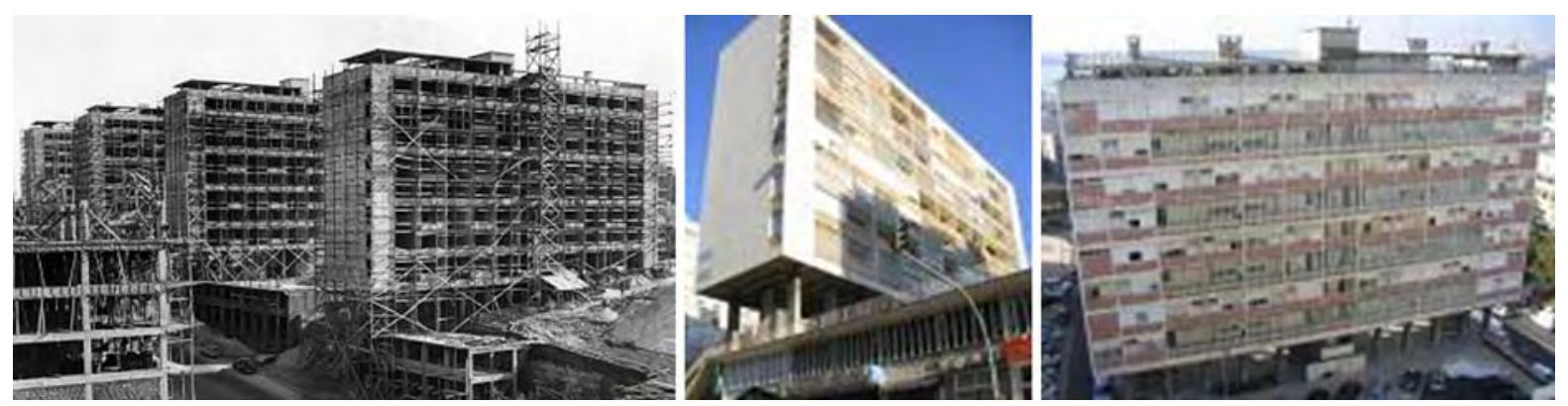

Fig. 7 General views of the building block under analysis 
expropriating and dividing up parcels of land for the new Avenue Infante Santo, which completed the ring created by De Gröer's Municipal Plan (1938-1948).

The block plan is rectangular with a width of $11.10 \mathrm{~m}$ and a length of $47.40 \mathrm{~m}$. The building has the height of 8 habitation storeys plus the pilotis height at the ground floor. The "free plan" also serves as a reference point as the house was designed with flexibility of use in mind. The main structural system (12 parallel plane frames) restricts the architecture. The layout of the units in the building block (floor type with 6 duplex apartments) was defined in accordance with the structural system. The distance between the frame's axes is $3.80 \mathrm{~m}$. Each frame is supported by two columns and has one cantilever beam on each side with a span of $2.80 \mathrm{~m}$, resulting in thirteen modules.

The structural plan is a good solution to the architectural objectives. "From the beginning of the studies, there was a ever-present concern to design a resistant structure that was simple, elegant and economic. And it looks like the objective was fully achieved because since the beginning of the work on the project there has been no need to change the primitive structure".

The structural plan for the housing block of the Unity Type A is comprised of 12 transversal reinforced concrete frames, each formed by two columns and three beams at each storey, two of which are in cantilever (Infante Santo residential building 1956).

The structural design was initially made for vertical loads only, without the columns' bending moment being taken into consideration. Later, new designs were developed which took into account, in a simplified manner, the horizontal loads corresponding to the wind, using the Cross method for calculating the distribution of the bending moments J. V. Dias (Miranda et al. 2005) did not take seismic action into consideration in his design. He refers to "the low probability of simultaneous occurrence of wind and seismic actions in the same direction and at their maximum intensity". Dias concludes that "this building-type has superior safety conditions than the majority of Lisbon's buildings".

At a later stage, the importance of taking seismic actions into account in the design of structural elements was recognized. A new design project was delivered, according to an article by Maria Amélia Chaves and Bragão Farinha published in "Técnica" Magazine. Horizontal forces, proportional to the floor's mass were considered in the frame nodes. However, structural analysis was only carried out in the transversal direction. The structural engineer concluded that wind forces induce larger demands than seismic loads, resulting in larger cross-sections.

The engineer, Ramos Cruz, responsible for the construction, developed a new design project for the 3rd parcel. He presented new calculations based on the original project, but he changed the original structural floor to a reinforced concrete slab. He proposes that, with this continuous rigid slab, rigid diaphragm behavior is guaranteed. Another modification is the introduction of reinforced concrete walls in the staircases on the ground floor, one of which extends the full height of the building. However, these RC elements were not detected in the technical visit to the building (Miranda et al. 2005).

\subsection{Description of the subject structure}

The building geometry and dimensions of the RC elements and infill walls were given in the original project (1950-1956), and were confirmed in the technical visits (Miranda et al. 2005). As already described in a previous section, the building under study has nine storeys and the structure is mainly composed of 12 plane frames oriented in the transversal direction (direction Y, as shown in Fig. 8). The

Fig. 8 Structural system (plan)

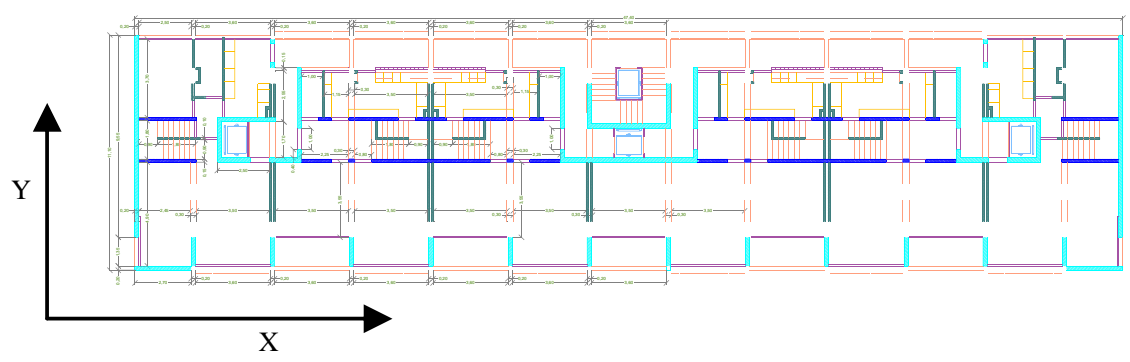


building was analyzed with a simplified plane model for each direction $(\mathrm{X}$-longitudinal direction, $\mathrm{Y}-$ transversal direction).

The 12 transversal plane frames have the same geometric characteristics for all beams and columns. However, three different frame-types (labeled A, B and $\mathrm{C}$ ) were identified, as a function of reinforcement detailing differences.

A peculiar structural characteristic of these buildings is the ground storey without infill masonry walls. This aspect has direct influence on the global structural behavior. Furthermore, at the ground storey the columns are $5.5 \mathrm{~m}$ in height. All the upper storeys have an inter-storey height of $3.0 \mathrm{~m}$.

In the two structural models (direction $\mathrm{X}$ and $\mathrm{Y}$ ), a concrete slab with a width of $1.25 \mathrm{~m}$ and a thickness of $0.20 \mathrm{~m}$ was considered. A detailed definition of the existing infill wall panels was described in the global structural models, namely, dimensions and position in the panel of openings, interface conditions between panel and surrounding RC elements, the properties of the masonry material. The global behavior curves for each masonry panel were estimated according to the Zarnic and Gostic (1998) empirical expressions.

For analysis of the building in the transversal direction (Y), an equivalent model was assumed. This was defined as the association of the three frame-types, interconnected by rigid strut bars, as shown in Fig. 9. In this global model, the geometric and mechanical characteristics of each frame are multiplied by the number of occurrences of each frame-type.

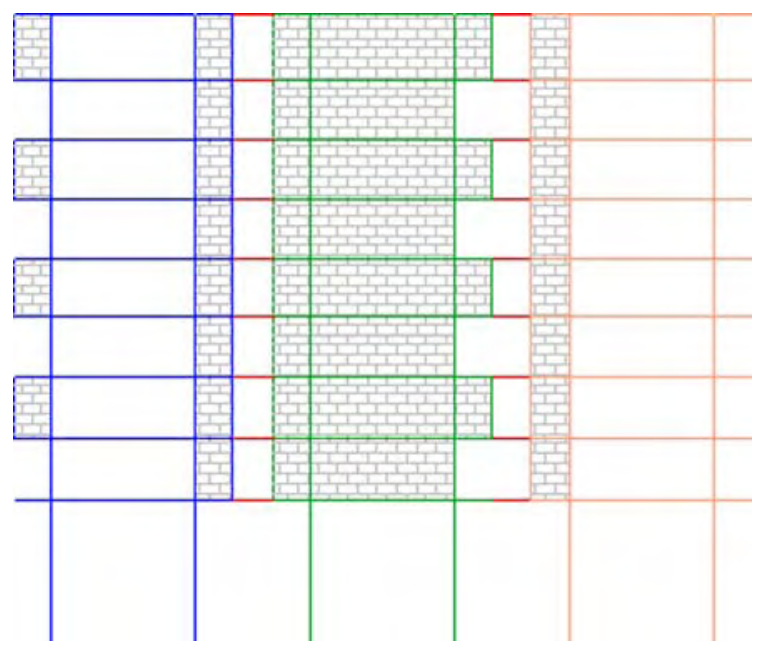

Fig. 9 Equivalent structural system for transversal direction (Y)

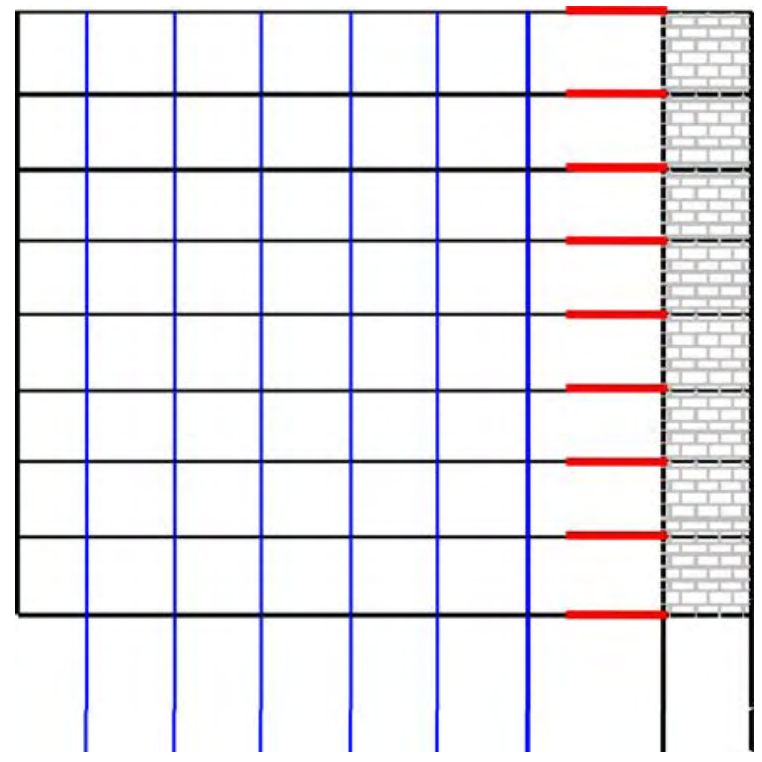

Fig. 10 Equivalent structural system for longitudinal direction (X)

For the longitudinal direction $(\mathrm{X})$ analysis, and because of the double symmetry in the plan, only one quarter of the building was studied. The global model of the structure is composed by six columns linked, at all storey levels, by the RC slabs. No full-bay infill panels exist in the longitudinal direction. Therefore, an external simplified global infill masonry model connected through rigid struts to the RC structure was considered, as shown in Fig. 10.

\subsection{Static loads, masses and damping}

For the numerical analyses, constant vertical loads distributed on beams were considered in order to simulate the dead load of the self-weight including $\mathrm{RC}$ elements and infill walls, finishing, and the corresponding quasi-permanent value of the live loads, giving a total value of $8.0 \mathrm{kN} / \mathrm{m}^{2}$.

The mass of the structure was assumed to be concentrated at storey levels. Each storey has a mass, including the self-weight of the structure, infill walls and finishings, and the quasi-permanent value of the live loads, of about 4 Mtons. For the dynamic analysis, the storey mass is assumed to be uniformly distributed across the floors.

A small value for the viscous damping ratio was considered (1\%) for each vibration mode in the 
numerical analyses. In fact, for this kind of structure, and for medium to high demand levels, the damping associated with the dynamic response is mainly associated with the damage induced in the structure. Therefore, and due to the fact that the non-linear behavior is thoroughly considered in the non-linear hysteretic structural and dynamic models, the contribution of the viscous damping to the response is of minor importance (Varum 2003).

For each structural model, a Rayleight damping matrix, with $1 \%$ damping ratio for the first two natural modes, was considered, according to

$[C]=\beta[K]+\alpha[M]$

where the coefficients $\beta$ and $\alpha$ are calculated such that $1 \%$ damping ratio in the first two modes of vibration is achieved. $[K]$ and $[M]$ are the stiffness and mass matrices of the structure, respectively.

\subsection{Natural frequencies and modes}

A first validation of structural numerical models can be achieved by comparing the experimentally measured and the analytically estimated natural frequencies.

Table 1 lists the first four natural frequencies computed for each building direction.

To validate the numerical building models, measurements were made in the two independent directions of the first natural structural frequency, using a seismograph, and the ambient vibration. The measured first frequency is indicated in brackets in Table 1.

A good agreement was found between the experimentally measured frequencies $(1.17 \mathrm{~Hz}$ for longitudinal direction and $1.56 \mathrm{~Hz}$ for transversal direction-Miranda et al. 2005) and the frequencies estimated with the structural numerical models $(1.08 \mathrm{~Hz}$ for longitudinal direction and $1.75 \mathrm{~Hz}$ for

Table 1 Natural frequencies for directions $\mathrm{X}$ and $\mathrm{Y}$

\begin{tabular}{lll}
\hline Modes & Frequencies $(\mathrm{Hz})$ & \\
\cline { 2 - 3 } & Longitudinal direction $(\mathrm{X})$ & Transversal direction (Y) \\
\hline 1st & $1.08(1.17)$ & $1.75(1.56)$ \\
2nd & 5.67 & 6.41 \\
3rd & 6.32 & 8.14 \\
4th & 8.10 & 8.80 \\
\hline
\end{tabular}
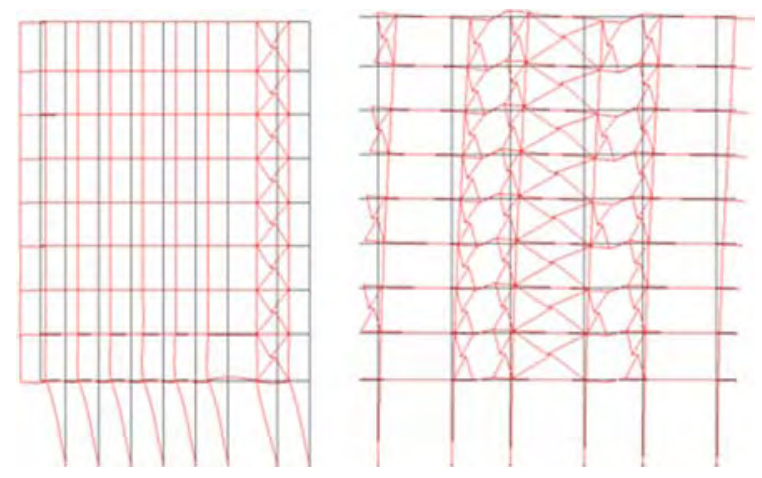

Fig. 11 Natural vibration modes $\left(f_{1, X}=1.08 \mathrm{~Hz}\right.$ and $f_{1, Y}=$ $1.75 \mathrm{~Hz})$

transversal direction), which constitutes the first validation of the numerical model. Figure 11 shows the first natural mode for each direction.

From the analysis of the first vibration shape modes in both directions it is clear that the seismic structural response will induce soft-storey mechanism behavior. This conclusion will be confirmed with the earthquake analysis results in the following sections (Fig. 12).

\subsection{Earthquake input signals}

Three artificial earthquake input series were adopted for the seismic vulnerability analysis of the building. The first series (A) was artificially generated for a medium/high seismic risk scenario in Europe (Carvalho et al. 1999), for various return periods (Table 2). The second and third series (B and C, respectively) were generated with a finite fault model for the simulation of a probable earthquake in Lisbon (Carvalho et al. 2004), calibrated with real seismic actions measured in the region of Lisbon. The earthquakes of the $\mathrm{B}$ and $\mathrm{C}$ series were scaled to the peak ground acceleration of series $\mathrm{A}$, for each return period. Table 2 details the peak ground acceleration and the corresponding return period for each earthquake's intensity.

\subsection{Analysis of results}

As observed in the analysis of the vibration shape modes, the structural response of the building, in both directions, clearly induces soft-storey mechanism behavior (at the ground floor level). This structural behavior leads to large inter-storey drift demands at 
Fig. 12 Accelerograms adopted: A, B and C
Serie A

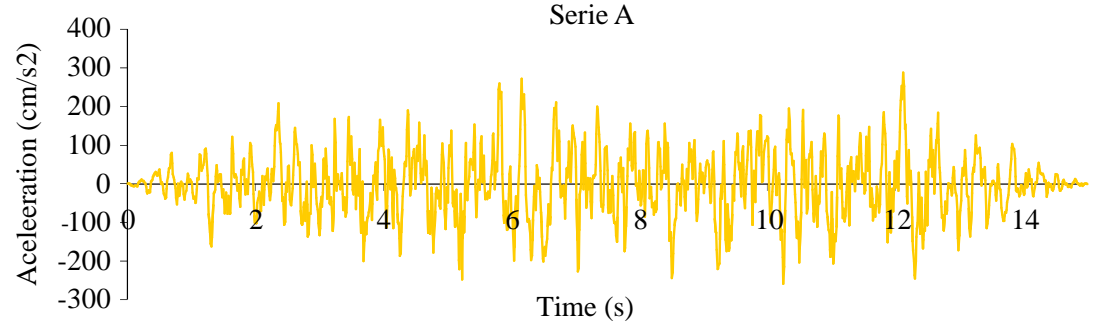

Serie B

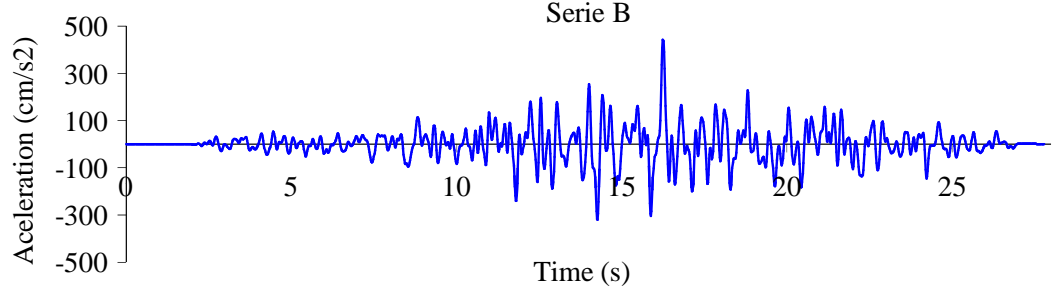

Time (s)

Serie C

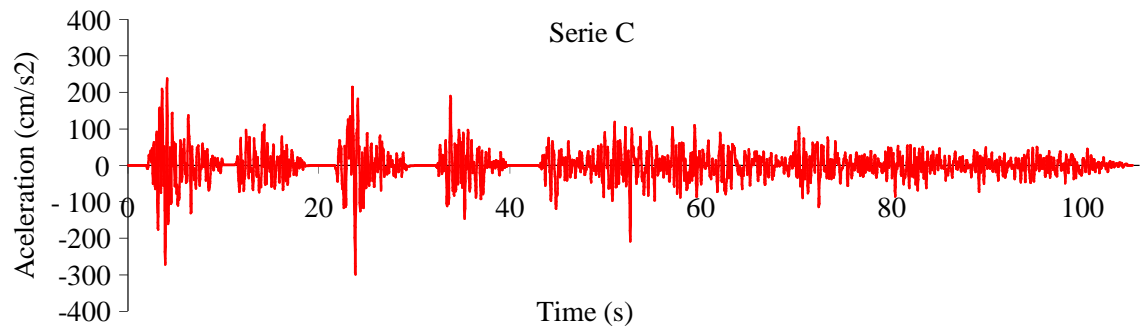

Table 2 Reference earthquake action (peak ground acceleration and corresponding return period)

\begin{tabular}{ll}
\hline $\begin{array}{l}\text { Return period } \\
\text { (years) }\end{array}$ & $\begin{array}{l}\text { Peak ground } \\
\text { acceleration }(\times \mathrm{g})\end{array}$ \\
\hline 73 & 0.091 \\
475 & 0.222 \\
975 & 0.294 \\
2,000 & 0.380 \\
3,000 & 0.435 \\
5,000 & 0.514 \\
\hline
\end{tabular}

the first storey, while the upper storeys show very low deformation levels.

Figures 13 and 14 illustrate, for the longitudinal and transversal direction respectively, the numerical results in terms of envelop deformed shape, maximum inter-storey drift, and maximum storey shear, for each earthquake input motion of the A series (73, $475,975,2000,3000,5000$ years return period).

From the analysis of the results in terms of building envelop deformed shape and inter-storey drift profile, for both directions, it can be concluded that the deformation demands are concentrated at the first storey level. In fact, the absence of infill masonry walls at the ground storey and the greater storey height $(5.60 \mathrm{~m}$ for the $1 \mathrm{st}$ storey and $3.00 \mathrm{~m}$ for the upper storeys), induces an important vertical structural irregularity, in terms of stiffness and strength.

For all the structural elements (columns and beams), and for all the seismic input action levels, the shear force demand assumes a value inferior to the corresponding shear capacity, which confirms the building's safety in shear.

From the numerical analyses performed, it was verified for the earthquake input motions that the infill masonry panels essentially reveal no damage. In fact, due to the building structural system and its behavior, on the one hand, and to the absence of masonry panels at the ground floor, on the other, the global deformation demand is concentrated at the ground floor, and, therefore, the majority of the infill masonry panels present a linear behavior.

\subsubsection{Vulnerability curves}

This section compares, for the three earthquake input motions, the vulnerability curves in terms of 
Fig. 13 Results for the longitudinal direction (X) and series A earthquakes: (a) envelop deformed shape; (b) maximum interstorey drift profile;

(c) maximum storey shear profile

Fig. 14 Results for the transversal direction $(\mathrm{Y})$ and series A earthquakes:

(a) envelop deformed shape; (b) maximum inter-storey drift profile; (c) maximum storey shear profile
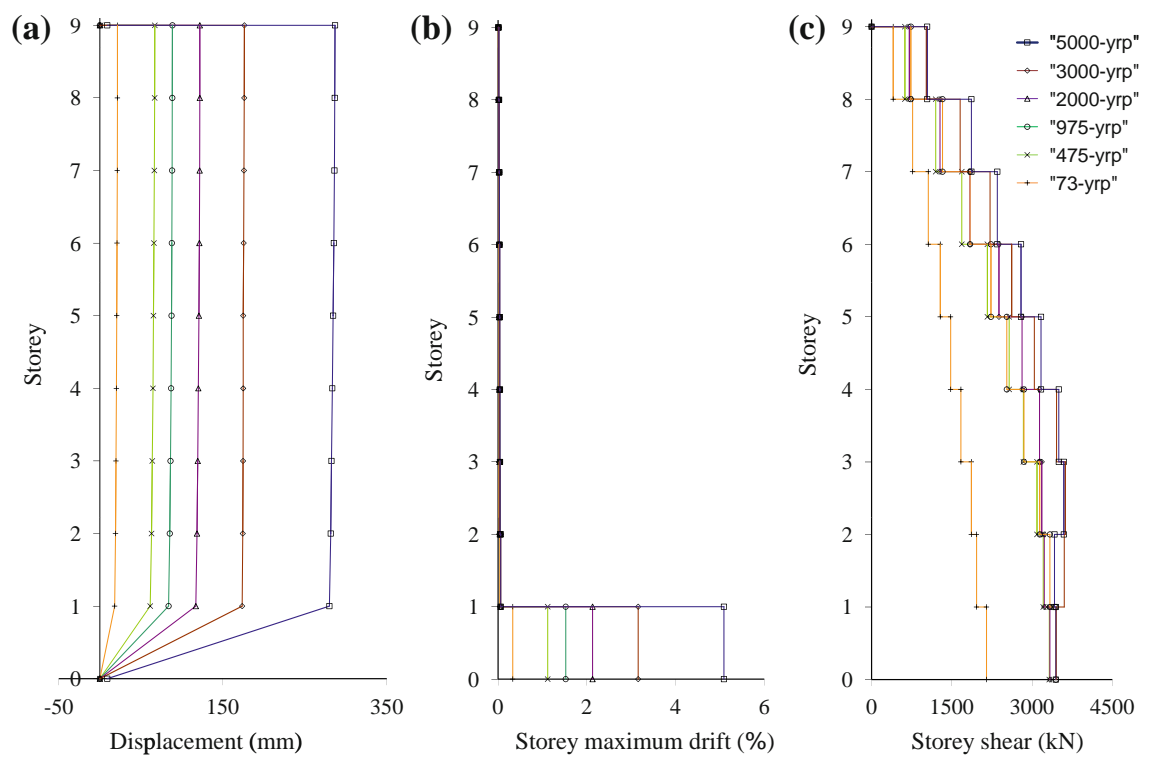
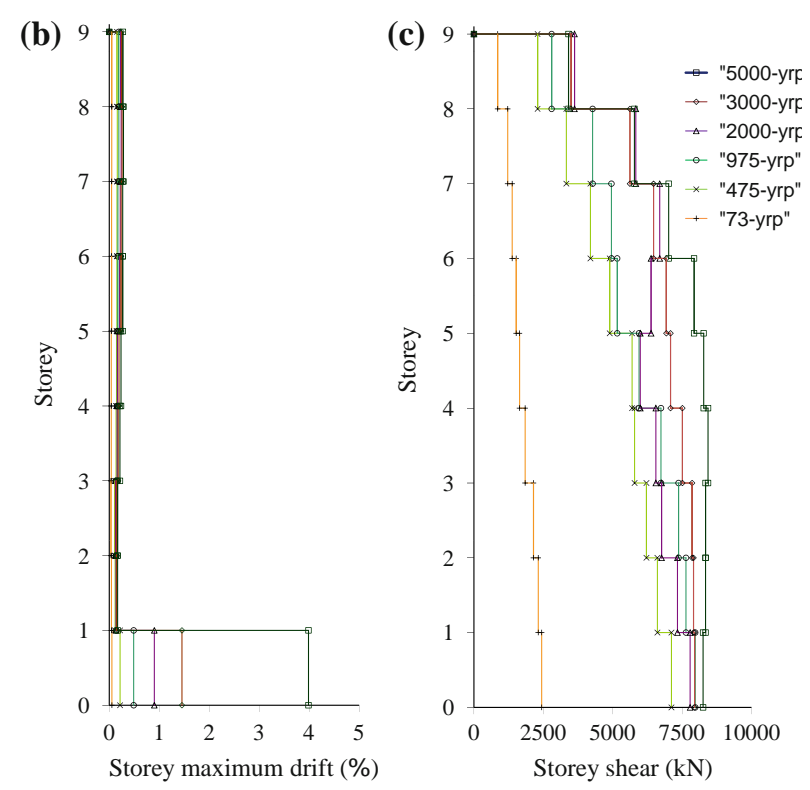

maximum 1st storey drift, maximum 1st storey shear and maximum top displacement, for the longitudinal and transversal directions.

Figures 15 and 16 compare the vulnerability curves for the transversal and longitudinal directions for the maximum 1st storey drift obtained from the numerical analysis. The results show that, for the 1st storey, the maximum inter-storey drift demand for the longitudinal direction is larger than for the transversal, thus confirming that the former is the building's most vulnerable direction.

Figures 17 and 18 show the vulnerability curves in terms of maximum 1st storey shear force. Figures 19 


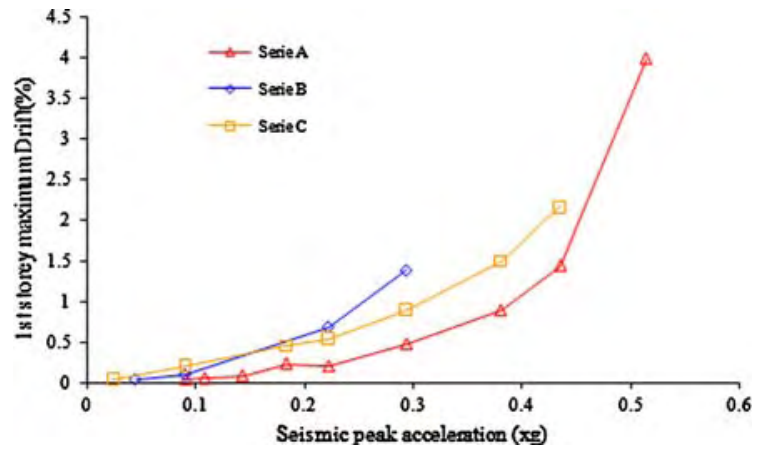

Fig. 15 1st storey drift versus peak acceleration (transversal direction-Y)

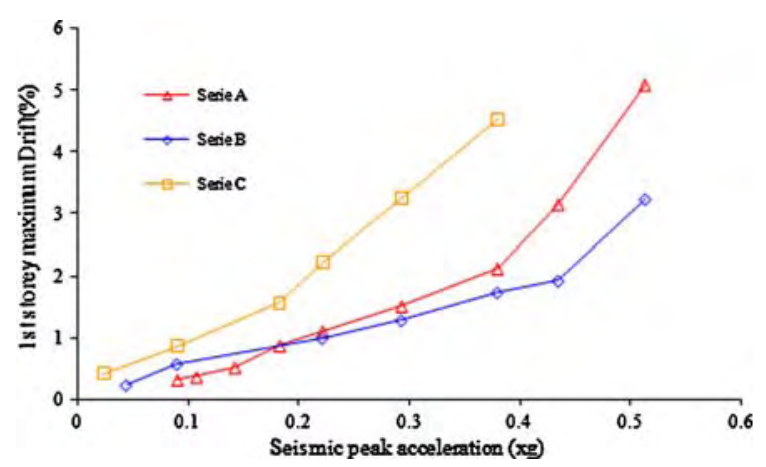

Fig. 16 1st storey drift versus peak acceleration (longitudinal direction-X)

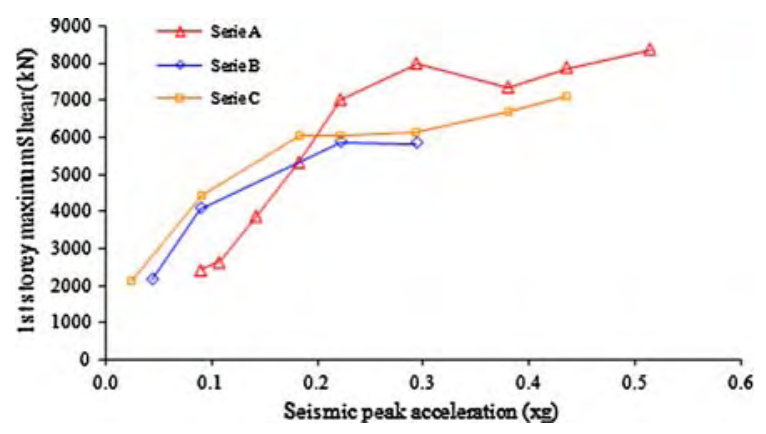

Fig. 17 1st storey shear versus peak acceleration (transversal direction-Y)

and 20 show the vulnerability curves obtained, in terms of maximum top displacement. Shear demand at the 1st storey does not increase for earthquake input actions larger than the one corresponding to a return period of 475 years. These only induce increasing deformation demands, as can be observed

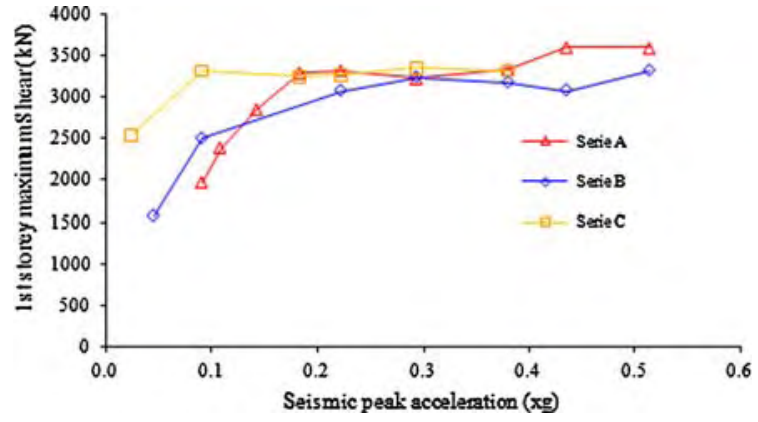

Fig. 18 1st storey shear versus peak acceleration (longitudinal direction-X)

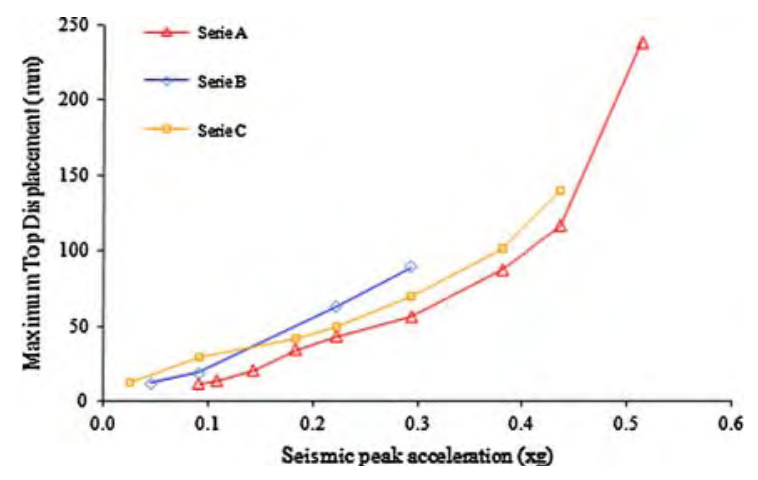

Fig. 19 Top displacement versus peak acceleration (transversal direction-Y)

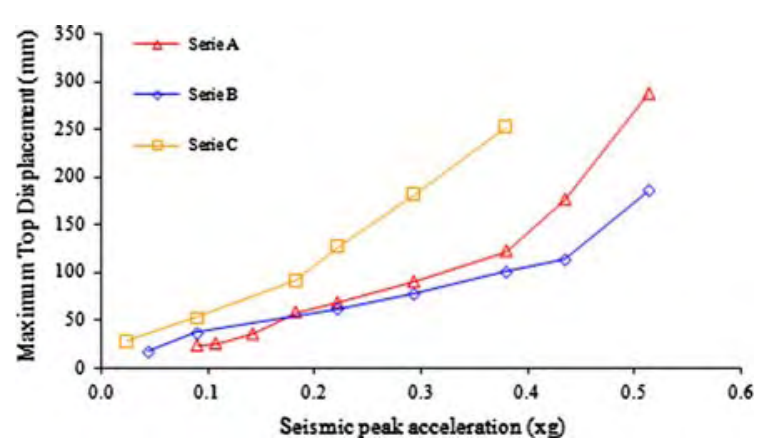

Fig. 20 Top displacement versus peak acceleration (longitudinal direction-X)

in the results relating to 1 st storey drift and top displacement. The results for certain earthquake series, and for higher intensity levels, were not included in the graphics, due to non-convergence of the numerical analyses associated with the large deformation demands. 


\subsubsection{Seismic safety assessment of the building}

As described in the previous section, the building structure was analyzed for each direction for three series of earthquakes of increasing intensities, in order to estimate deformation demands, and consequently damage levels.

The VISION-2000 (1995) document proposes performance objectives for buildings and for three performance levels (called: Basic, Essential Hazardous, and Safety Critical). For the building under study, and due to the nature of its use, the structural safety was investigated for the Basic Performance Objectives proposed by VISION-2000 (see Table 3, where the performance objectives are marked with an "X").

The results obtained allow verification of the safety according to the hazard levels specified, as, for example, in the VISION-2000 (1995) and in the ATC-40 (1996) documents. Tables 3 and 4 show the acceptable drift limits, for each structural performance level, according to the ATC-40 and in VISION 2000 proposals, respectively.

Figures 21 and 22 show the vulnerability functions in terms of maximum 1st storey drift, presented in the previous section, with an indication of the safety limits proposed in the ATC-40 and VISION-2000 recommendations (as summarized in Tables 3 and 4, respectively).

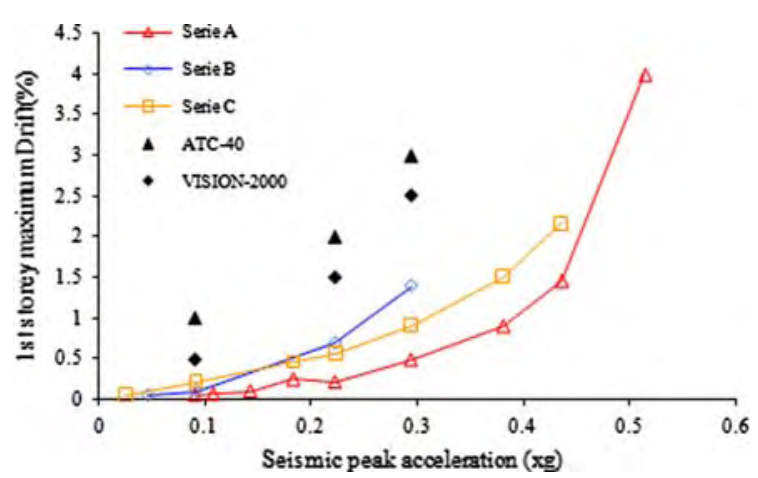

Fig. 21 1st storey drift versus peak acceleration and safety limits (transversal direction-Y)

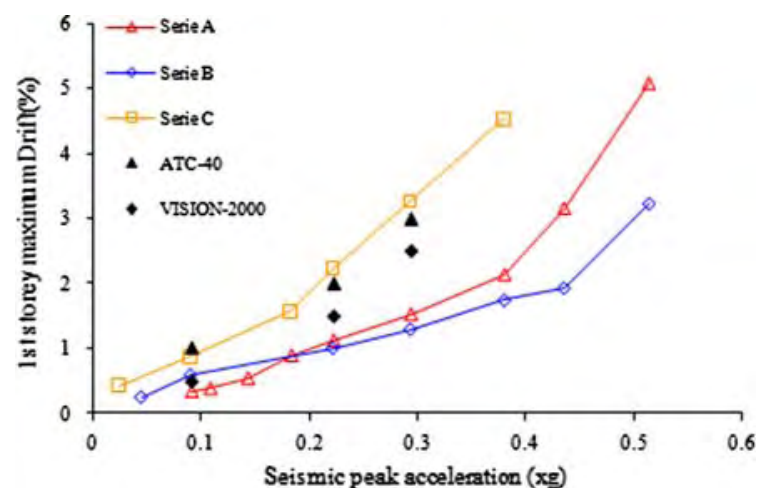

Fig. 22 1st storey drift versus peak acceleration and safety limits (longitudinal direction-X)
Table 3 Basic

Performance Objectives for buildings according to

VISION-2000 (1995)

\begin{tabular}{|c|c|c|c|c|c|}
\hline & & Fully operational & Operational & Life safe & Near collapse \\
\hline \multirow{4}{*}{$\begin{array}{l}\text { Earthquake } \\
\text { design level }\end{array}$} & Frequent (43-yrp) & & & & \\
\hline & Occasional (72-yrp) & & $\mathrm{X}$ & & \\
\hline & Rare (475-yrp) & & & $\mathrm{X}$ & \\
\hline & $\begin{array}{l}\text { Very rare } \\
\quad(970-2000 \text { yrp })\end{array}$ & & & & $\mathrm{X}$ \\
\hline
\end{tabular}

Table 4 Storey drift limits according to the (a) ATC-40 (1996), (b) VISION-2000 (1995)

\begin{tabular}{|c|c|c|c|c|}
\hline & \multicolumn{4}{|l|}{ Performance level } \\
\hline & Immediate occupancy & Damage control & Life safety & Structural stability \\
\hline \multicolumn{5}{|c|}{ (a) Storey drift limits according to the ATC-40 (1996) } \\
\hline \multirow[t]{2}{*}{ Drift limit } & $1 \%$ & $1-2 \%$ & $2 \%$ & $0.33 \frac{V_{i}}{P_{i}} \approx 7 \%$ \\
\hline & Fully operational & Operational & Life safe & Near collapse \\
\hline \multicolumn{5}{|c|}{ (b) Storey drift limits according to the VISION-2000 (SEAOC 1995) } \\
\hline Drift limit & $0.2 \%$ & $0.5 \%$ & $1.5 \%$ & $2.5 \%$ \\
\hline
\end{tabular}


Comparing the maximum storey drift demands with the safety limits proposed in the ATC-40 and VISION2000 recommendations, the conclusion may be drawn that building safety is guaranteed in the transversal direction (Y), for the three earthquake input series considered. For the longitudinal direction (X), safety is guaranteed for series $\mathrm{A}$ and $\mathrm{B}$, but not for series $\mathrm{C}$.

\section{Concluding remarks}

This paper has investigated the global structural safety of a modern architecture style building in Lisbon, Portugal. The analysis performed demonstrates the capacities of the models and of the integrated computer program, PORANL, to represent the global response and seismic behavior of RC building structures. Specifically, the non-linear bending behavior of slender RC elements, and the influence of the infill masonry panels in the global seismic response of such buildings were simulated numerically.

Although the first numerical results generally indicate the safety of the building for the Basic Safety Objectives, detailed in international seismic recommendations (ATC-40 and VISION-2000), it should be pointed out that additional analyses will have to be performed to validate these first conclusions.

The input motion earthquakes adopted for these analyses cannot be fully representative of all the probable earthquake actions in Lisbon. Additional analyses should be performed using other earthquake input motions.

The model adopted for these analyses does not consider geometric non-linearity, which can significantly increase the moments in columns and global storey lateral deformations (drifts). Therefore, and in order to guarantee the seismic safety of the building, it is judged focal to verify the results using a model that considers such geometrical non-linearities.

The high vulnerability of this building structural typology, which exists in a considerable number in Lisbon, is evident. The high seismic risk associated to these buildings in the Lisbon metropolitan area could be significantly reduced by the adoption of suitable retrofitting solutions. The seismic retrofitting of these buildings can be performed economically, since intervention in this typology can be instigated at the ground storey, usually without infill masonry walls, for example with bracing systems and, eventually, in combination with energy dissipation devices. The building assessment and design of a retrofitting solution should always be followed by an efficiency evaluation.

\section{References}

ATC-40, Seismic evaluation and retrofit of concrete buildings-Applied Technical Council, California Seismic Safety Commission, Report No. SSC 96-01 (two volumes), Redwood City, California, US (1996)

Carvalho, E.C., Coelho, E., Campos-Costa, A.: Preparation of the full-scale tests on reinforced concrete frames-Characteristics of the test specimens, materials and testing conditions. ICONS report, Innovative Seismic Design Concepts for New and Existing Structures, European TMR Network-LNEC, Lisbon (1999)

Carvalho, A., Campos-Costa, A., Oliveira, C.S.: A stochastic finite-fault modelling for the 1755 Lisbon earthquake, 13th World Conference on Earthquake Engineering Vancouver, B.C., Canada (2004)

Costa, A.G.: Análise Sísmica de Estruturas Irregulares. PhD Thesis, Civil Engineering Department, University of Porto (1989) (in Portuguese)

Infante Santo residential building (Block 3), Drawings and Descriptive and Justificative Memoir (1956)

Miranda, L., Rodrigues, H., Fonseca, J., Costa, A.: Relatório de Inspecção ao Bloco 3 do complexo do Infante Santo, Technical report, Civil Engineering Department, University of Porto (2005) (in Portuguese)

Rodrigues, H.: Desenvolvimento e Calibração de Modelos Numéricos para a Análise Sísmica de Edifícios. MSc Thesis, Civil Engineering Department, University of Porto, Portugal (2005) (in Portuguese)

Rodrigues, H., Varum, H., Costa, A.: Numeric Model to account for the influence of infill masonry in the RC Structures Behaviour, Congreso Métodos Numéricos en Ingeniería (2005)

Varum, H.: Modelo numérico para análise de pórticos planos de betão armado. MSc Thesis, Civil Engineering Department, University of Porto (1996) (in Portuguese)

Varum, H.: Seismic assessment, strengthening and repair of existing buildings. PhD Thesis, Department of Civil Engineering, University of Aveiro (2003)

VISION-2000, Performance based seismic engineering of buildings, Part 2: Conceptual framework-Vision 2000 Committee, Structural Engineers Association of California, Sacramento, California (1995)

Zarnic, R., Gostic, S.: Non-linear modelling of masonry infilled frames, 11th ECEE, Paris, France. A.A. Balkema, Rotterdam (1998). ISBN 9054109823 